Article

\title{
Detection of Eccentricity Faults in Five-Phase Ferrite-PM Assisted Synchronous Reluctance Machines
}

\author{
Carlos López-Torres ${ }^{1}$, Jordi-Roger Riba ${ }^{1, *}$, Antonio Garcia ${ }^{1}$ and Luís Romeral ${ }^{2}$ \\ 1 Electrical Engineering Department, Universitat Politècnica de Catalunya, 08222 Terrassa, Spain; \\ carlos.lopez@mcia.upc.edu (C.L.-T.); garciae@ee.upc.edu (A.G.) \\ 2 Electronic Engineering Department, Universitat Politècnica de Catalunya, 08222 Terrassa, Spain; \\ romeral@eel.upc.edu \\ * Correspondence: riba@ee.upc.edu; Tel.: +34-93-7398-365
}

Academic Editor: David He

Received: 11 April 2017; Accepted: 25 May 2017; Published: 31 May 2017

\begin{abstract}
Air gap eccentricity faults in five-phase ferrite-assisted synchronous reluctance motors (fPMa-SynRMs) tend to distort the magnetic flux in the air gap, which in turn affects the spectral content of both the stator currents and the ZSVC (zero-sequence voltage component). However, there is a lack of research dealing with the topic of fault diagnosis in multi-phase PMa-SynRMs, and in particular, those focused on detecting eccentricity faults. An analysis of the spectral components of the line currents and the ZSVC allows the development of fault diagnosis algorithms to detect eccentricity faults. The effect of the operating conditions is also analyzed, since this paper shows that it has a non-negligible impact on the effectivity and sensitivity of the diagnosis based on an analysis of the stator currents and the ZSVC. To this end, different operating conditions are analyzed. The paper also evaluates the influence of the operating conditions on the harmonic content of the line currents and the ZSVC, and determines the most suitable operating conditions to enhance the sensitivity of the analyzed methods. Finally, fault indicators employed to detect eccentricity faults, which are based on the spectral content of the stator currents and the ZSVC, are derived and their performance is assessed. The approach presented in this work may be useful for developing fault diagnosis strategies based on the acquisition and subsequent analysis and interpretation of the spectral content of the line currents and the ZSVC.
\end{abstract}

Keywords: air gap; eccentricity; fault diagnosis; finite-element method; synchronous reluctance machine; multi-phase machine

\section{Introduction}

In recent years, SynRMs (synchronous reluctance machines) have become popular because of the volatility of the rare-earth PM (permanent magnet) price, concerns about the risk of supply [1], or the demand of highly-efficient machines. These factors are promoting SynRMs and ferrite-PM assisted SynRMs (fPMa-SynRMs) to be competitors of induction machines [2] and PM synchronous machines [3] in many applications requiring a high efficiency and torque density, wide constant-power speed range or overload capability [4]. Ferrite-assisted SynRMs rely on abundant and low-cost ferrite PMs, offering a good option since they generate both magnetic and reluctance torques [5]. PMa-SynRMs offer a lower cost and higher reluctance torque than IPM (interior-PM) motors, since PMa-SynRMs require a smaller volume of magnets because the reluctance torque is the main component of the total torque. Due to the reluctance torque, SynRMs present a higher torque ripple compared to other motors; however, by applying selected rotor steps, rotor skewing, or asymmetric flux barriers, the pulsation of the torque can be reduced [2]. 
Fault diagnosis methods for rotating machinery based on on-line condition monitoring are currently the object of a major research effort. This approach ensures the reliable and safe operation of the equipment involved, while minimizing the occurrence of unscheduled and unexpected failures [6], thus reducing economic losses [7] and the occurrence of serious accidents.

Air gap eccentricity is among the most frequent faults. It can have multiple origins, such as bearing wear, stator core ovality, rotor shaft bending, mechanical resonance [7], or partial demagnetization of the magnets in the rotor [8]. Eccentricity produces an uneven distribution of the air gap [9]. A faulty motor presents a disturbed operation that shortens its lifetime. The static eccentricity can be due to an inappropriate positioning of the rotor, so the rotation center coincides with the symmetry axis of the rotor but is displaced from the symmetry axis of the stator [7], so the minimum position of the air gap remains fixed in space. Dynamic eccentricity is produced when the rotation center is not concentric with the symmetry axis of the rotor and the minimum position of the air gap changes with time [9]. Mixed eccentricity occurs when both static and dynamic eccentricity coexist.

It is a recognized fact that air gap asymmetry produces new harmonic components in the air gap flux, which are due to harmonics of the stator and rotor magneto-motive forces (mmf) [9], changes in air gap permeance [10], and changes in the air gap flux due to the permanent magnets in the rotor. This non-uniformity of the air gap permeance generates harmonic components that can be seen in the spectra of the magnetic flux density, thus increasing the torque ripple and affecting the harmonics of torque and speed. Eccentricity in SynRMs generates a radial force due to the air gap asymmetry, which produces mechanical stress on the bearings [4]. Air gap fluctuations modify motor inductances and thus, the stator current harmonics [10,11], which can be used to apply a noninvasive fault detection approach [11].

Air gap eccentricity can be detected by applying different strategies, including spectral analysis of the line voltage at disconnection, spectral vibration analysis, acoustic analysis [12,13], thermal analysis [14], air gap flux analysis, and MCSA (motor current signature analysis); the latter being the most widely applied since it is a noninvasive technique that can be applied for on-line fault detection. MCSA is a widely applied technique [15-17] based on the monitoring of the spectral content of the line currents of the motor when operating under a steady-state condition, so it assumes that any change in the representative harmonic components is due to the presence of air gap eccentricity [18]. MCSA has been applied in different types of electrical motors, including induction machines, permanent magnet motors, and SynRMs [18], although it has recently been reported that this approach can lead, in some circumstances, to false indications [19]. In addition, it is known that the current loops of the electronic drive can influence the amplitudes of the harmonics of the stator currents, thus hindering the diagnosis based on an analysis of the stator currents harmonics [20].

Air gap asymmetry faults may be also detected by analyzing the ZSVC (zero-sequence voltage component). This approach is advantageous since the ZSVC can be decoupled from the effects of the electronic drive and the controller [20]. Although the fault detection method based on the ZSVC involves an accessible central point of the stator windings, this arrangement is frequently applied in fault-tolerant motor drives. The results presented in [20,21] for PMSMs (permanent magnet synchronous machines) prove that the ZSVC approach has a better accuracy and sensitivity than the analysis of the stator currents spectra, particularly when the motor operates under low-speed conditions.

In the technical literature, there are many works that analyze the effects of air gap eccentricity faults, but few of them are related to PMa-SynRMs [9,22,23]. Most of the works dealing with fault detection in PMa-SynRMs are either based on an analysis of the torque developed by the machine [4,24], although this method has several drawbacks due to its nonlinear relationship with the severity of the fault, or apply an off-line approach [25], with the associated disadvantages.

Instead, this work focuses on an analysis of the spectral content of both the line currents and the ZSVC in five-phase fPMa-SynRMs under the effects of air gap asymmetries, which permits the application of a straightforward on-line fault diagnosis strategy. The finite element method (FEM) has 
been applied to analyze the different machines, since FEM is a recognized simulation method that allows an accurate electromagnetic analysis [26] and assists in the optimal design process of electrical machines [27]. FEM also allows one to compute the values of key machine variables, and thus, permits an analysis of the behavior of suitable parameters to be used in fault detection approaches to characterize the motor failures under analysis [20].

The detection of failures in PMaSynRMs is a hot topic due to the growing interest of these machines for vehicular traction applications. The particular geometry of such motors hinders the on-line detection of eccentricity faults. This paper proves that when selecting favorable operating points, the detection is possible. This paper also proposes an on-line eccentricity fault detection approach, which includes the calculation of fault indicators from the spectral content of the stator currents and the ZSVC. The calculation process of such indicators presents a low computational burden, which is a requisite for on-line applications.

\section{The Analyzed Machine}

This paper deals with a PMa-SynRm, whose main features are summarized in Table 1.

Table 1. Main features of the analyzed fPMa-SynRM.

\begin{tabular}{cc}
\hline Features & Value \\
\hline Rated power $(\mathrm{kW})$ & 3.5 \\
Rated torque $(\mathrm{N} \cdot \mathrm{m})$ & 5.7 \\
Rated speed $(\mathrm{rev} / \mathrm{min})$ & 5000 \\
Rated current $(\mathrm{ARMS})$ & 4 \\
Rated voltage $(\mathrm{VRMS})$ & 240 \\
Number of phases & 5 \\
Number of slots & 60 \\
Pole pairs $(\mathrm{p})$ & 12 \\
Slots $/$ pole/phase $(\mathrm{q})$ & 1 \\
Conductors per slot & 60 \\
Layer type & Double layer \\
Airgap width $(\mathrm{mm})$ & 0.3 \\
Permanent magnets & Ferrite HF 30/26 \\
Magnetic steel & M330-35A \\
$d$-axis inductance $(L d, \mathrm{mH})$ & $59.7_{\text {no_current }}-15.9$ max_current \\
-axis inductance $(L q, \mathrm{mH})$ & $15.2_{\text {no_current }}-11.8_{\text {max_current }}$ \\
\hline
\end{tabular}

The analyzed motor has a fault-tolerant winding, since each slot only accommodates a unique phase, as shown in Figure 1. In addition, the combination of the low current design and the large inductances (each slot includes 60 conductors) reduces the risk of high short-circuit currents.
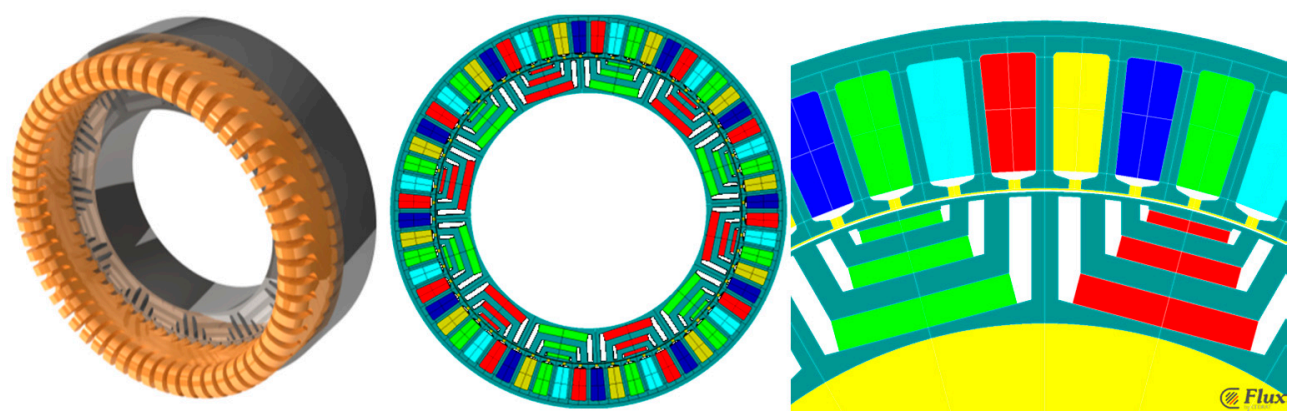

(a)

Figure 1. Cont. 


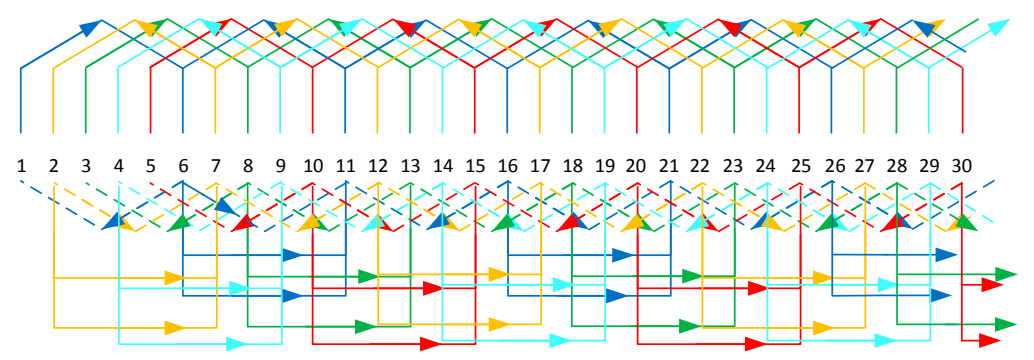

(b)

Figure 1. FEM model of the analyzed machine. (a) Layout of the machine. (b) Half winding of the five-phase 60-slots machine with a double layer and constant pitch with $q=1$.

The results presented in this paper are based on a healthy and a faulty machine with a static eccentricity of $40 \%$ of the air gap length. It is noted that although this paper analyzes the effects of static eccentricity faults, dynamic eccentricity produces comparable results, and thus similar conclusions apply for both eccentricity types.

The $d$ axis is taken as the direction of maximum magnetic flux in the rotor, which is the direction of the magnetic flux in the rotor following the magnetic path. The minimum flux corresponds to the $q$ axis, corresponding to the direction of the magnetic flux crossing the air barriers, as shown in Figure 2 .
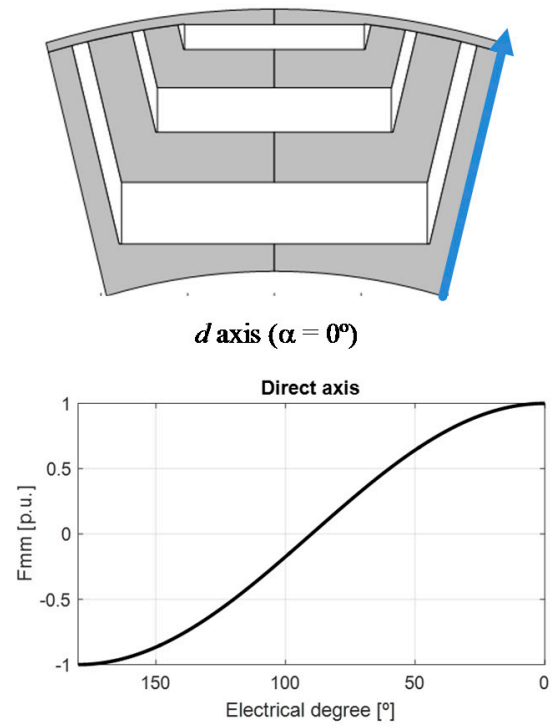

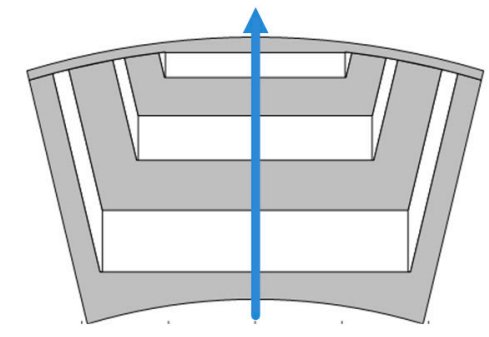

$q$ axis $\left(\alpha=90^{\circ}\right)$

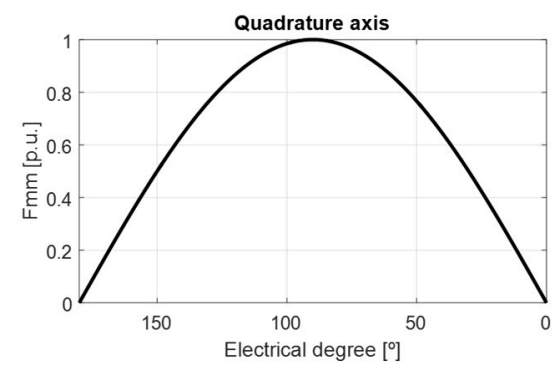

Figure 2. Direct $(d)$ and quadrature $(q)$ axes and the $m m f$ (magneto-motive force) as a function of the electrical angle of a SynRM.

It is noted that the currents in the $d q$ reference frame $\left(i_{d}, i_{q}\right)$ can be calculated from the line currents $\left(i_{a}, i_{b}, i_{c}, i_{d}, i_{e}\right)$ as:

$$
\left[\begin{array}{c}
i_{d} \\
i_{q}
\end{array}\right]=\frac{2}{5}\left[\begin{array}{ccccc}
\cos \left(\theta_{m}\right) & \cos \left(\theta_{m}-\frac{2 \pi}{5}\right) & \cos \left(\theta_{m}-\frac{4 \pi}{5}\right) & \cos \left(\theta_{m}+\frac{4 \pi}{5}\right) & \cos \left(\theta_{m}+\frac{2 \pi}{5}\right) \\
\sin \left(\theta_{m}\right) & \sin \left(\theta_{m}-\frac{2 \pi}{5}\right) & \sin \left(\theta_{m}-\frac{4 \pi}{5}\right) & \sin \left(\theta_{m}+\frac{4 \pi}{5}\right) & \sin \left(\theta_{m}+\frac{2 \pi}{5}\right)
\end{array}\right] \cdot\left[\begin{array}{c}
i_{a} \\
i_{b} \\
i_{c} \\
i_{d} \\
i_{e}
\end{array}\right]
$$

and the current angle is calculated as:

$$
\alpha=\operatorname{tg}^{-1}\left(\frac{i_{q}}{i_{d}}\right)
$$


Figure 3 shows the five currents and the $m m f$ distribution for a given time instant in both the $d$ and $q$ axes.

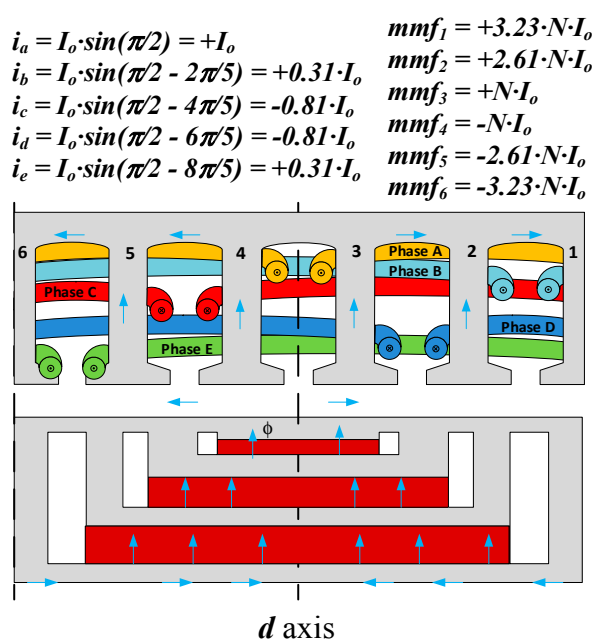

(a)

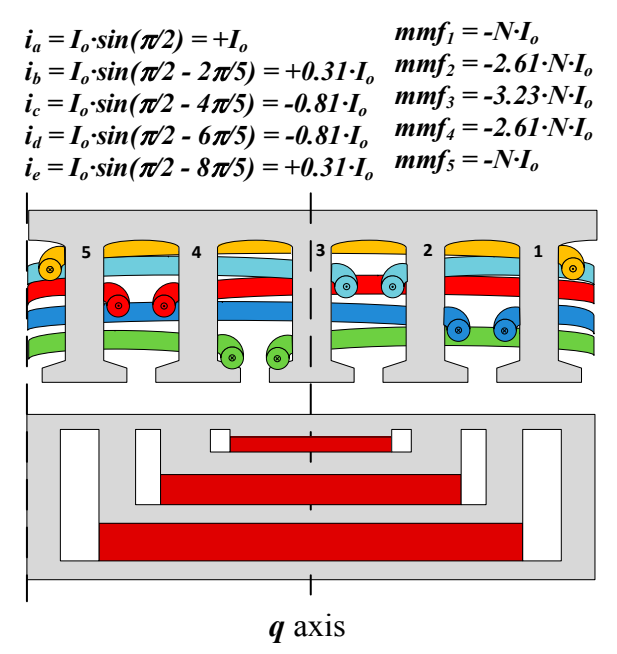

(b)

Figure 3. One pole of a five-phase fPMa-SynRM positioned in the direct $(d)$ and quadrature $(q)$ axes and the $m m f$ distribution. (a) $d$-axis position. (b) $q$-axis position.

The permanent magnets in the rotor are placed in the negative direction of the $q$ axis, so when the motor is positioned in the $d$ axis, the net flux through the stator windings due to the permanent magnets is null. This is illustrated in Figure 3a, which shows one pole of a five-phase machine positioned in the $d$ axis when neglecting the effects of the stator currents. The total flux through the windings is null since the flux in phase A is also null due to the arrangement shown in Figure 3a, whereas phases B and $\mathrm{E}$, and $\mathrm{C}$ and $\mathrm{D}$, are complementary, so the net flux is zero.

It is known that the winding configuration in rotating field machines greatly impacts the power capability and the spectral content of both the $m m f$ and back-emf. These effects are reflected in the harmonic composition of the line currents and the ZSVC [21].

\section{Detection of Air Gap Eccentricity Faults in PMa-SynRM from the Stator Currents Spectrum}

The research dealing with a three-phase SynRM found in [18] and [28] shows that static eccentricity faults induce triplen harmonic frequencies in the stator currents, although it is known that supply unbalance may also induce such harmonic components, thus hindering the interpretation. These works also conclude that dynamic eccentricity does not generate new harmonic components in the stator currents, although it modifies the odd harmonics. Static eccentricity induces harmonic components in the stator current harmonics which can be localized as [9,10,29-31]:

$$
f_{\text {Eccentricity }}=f_{s} \cdot\left(1 \pm \frac{k}{p}\right) k=1,2,3, \ldots
$$

where $p$ is the number of pole pairs of the motor and $f_{s}$ is the supply frequency. Therefore, from (3), it is deduced that eccentricity faults can induce particular fractional harmonic frequencies in the stator currents spectra that can be used for diagnosis purposes. The set of harmonics predicted by (3) is present under both stationary and nonstationary operating conditions.

The line currents are already measured by the current probes included in the drive supplying the PMa-SynRM. Therefore, no additional sensors are necessary. Since, as explained, the amplitude of the stator currents harmonics may be altered by the current loops of the electronic drive, it can hinder the diagnosis from the study of the stator currents. Therefore, the ZSVC-based method is also applied in this work. 


\section{Detection of Air Gap Eccentricity Faults in PMa-SynRM from the ZSVC Spectrum}

To measure the ZSVC, the central point of the wye-connected stator windings must be accessible [21]. In addition, a balanced three-phase inexpensive resistor network is required to generate an artificial neutral point. This approach is compatible with fault tolerant drives adding an extra inverter branch to replace the failed phase, which is connected to the central point of the windings [32,33]. In this way, the ZSVC injected by the electronic drive can be removed from the neutral voltage of the PMa-SynRM [34].

When dealing with a symmetric and healthy machine, according the layout shown in Figure 4, the fundamental harmonic of the $v_{0, m}$ zero-sequence voltage component measured between the artificial neutral point and the central point of the stator windings can be expressed as [34]:

$$
v_{0, m}=-\frac{1}{5}\left(\frac{d \lambda_{a}}{d t}+\frac{d \lambda_{b}}{d t}+\frac{d \lambda_{c}}{d t}+\frac{d \lambda_{d}}{d t}+\frac{d \lambda_{e}}{d t}\right)=-\frac{d \lambda_{P M, 0}}{d t}
$$

where $\lambda_{P M, 0}$ is the zero-sequence flux component produced by the permanent magnets.

In the case of a salient machine affected by an eccentricity fault, an additional term appears in (4) due to the changing air gap in the phase inductances.

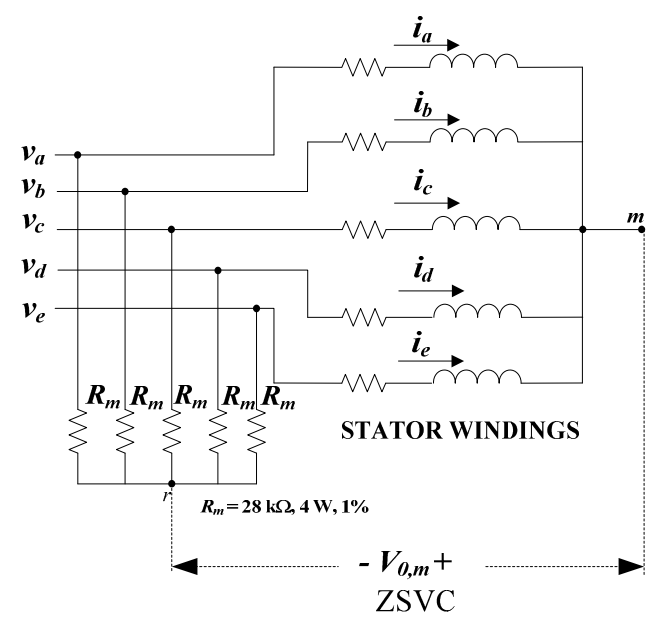

Figure 4. Connection realized to measure the ZSVC using a five-phase balanced resistor network to generate the artificial neutral point.

\section{Results}

Both the stator currents spectra and the ZSVC spectra of the fPMa-SynRM described in Section 2 are analyzed when the machine operates under healthy and air gap eccentricity fault conditions. The results presented in this section are based on two-dimensional FEM models built and calculated by means of the FLUX ${ }^{\circledR} 12.1$ rotating machines software, whereas the post-processing analysis was developed with the Matlab-2015b ${ }^{\circledR}$ software package. The two-dimensional mesh of the analyzed PMa-SynRM models comprises about 72,652 triangular elements. The supply frequency considered for simulation purposes was set to $500 \mathrm{~Hz}$ for all analyzed machines. A total of 60 electrical cycles were simulated with a sampling frequency of $120 \mathrm{kHz}$, thus obtaining a total of 7200 sample points, with 120 points in each electrical period.

\subsection{Motor Working under Rated Operating Conditions}

The first study focuses on the detection of eccentricity faults when the analyzed fPMa-SynRM operates under rated conditions, that is, $4 \mathrm{~A}_{\mathrm{RMS}}, 3.5 \mathrm{~kW}, 240 \mathrm{~V}_{\mathrm{RMS}}, 5000 \mathrm{rev} / \mathrm{min}$, and $65^{\circ}$ current angle (between $d-0^{\circ}$ and $q-90^{\circ}$ axes). Figure 5 shows the spectral content of the line currents of the analyzed fPMa-SynRM under healthy and $40 \%$ static eccentricity conditions. 


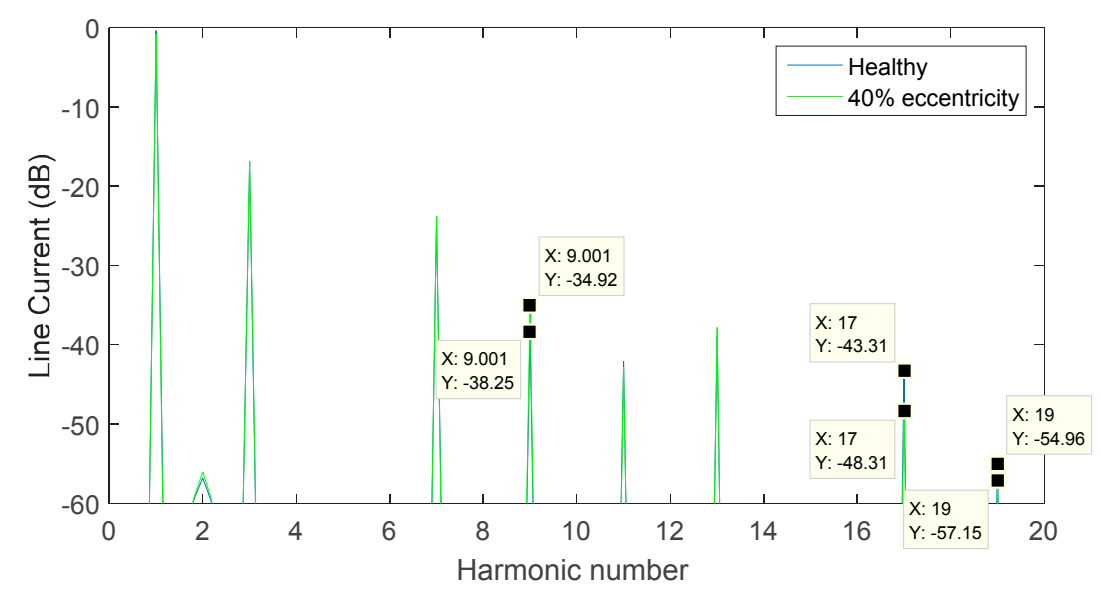

Figure 5. Rated operating conditions. Spectral content of the line currents. Healthy machine and faulty machine with $40 \%$ eccentricity.

The results presented in Figure 5 show minor differences between the spectral content of healthy and faulty machines, and it is thus difficult to detect eccentricity faults from the analysis of the line currents when the motor operates under rated conditions. The low discrimination attained between healthy and faulty conditions by the method based on the stator currents is attributed to the high reluctance path of the magnetic flux due to the combined effect of the saturation of the rotor segments placed between the flux barriers and the flux crossing the flux barriers. This reluctance takes similar values to those of the air gap, thus hindering the discrimination of the method based on the analysis of the stator currents spectra.

Figure 6 shows the spectral content of the ZSVC of the analyzed fPMa-SynRM under healthy and $40 \%$ static eccentricity conditions.

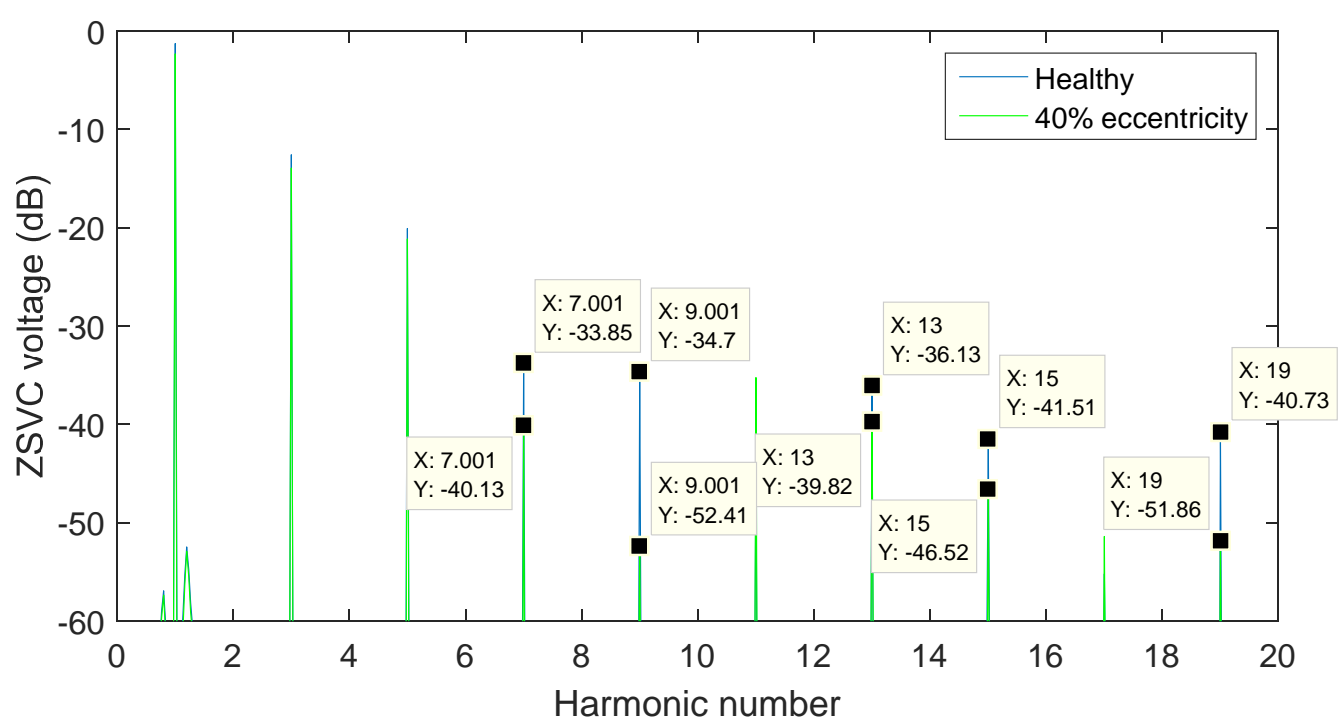

Figure 6. Rated operating conditions. Spectral content of the ZSVC. Healthy machine and faulty machine with $40 \%$ eccentricity.

It is noted that both the stator currents and ZSVC spectra are normalized with respect to the maximum value of the respective waveform. The results presented in Figure 6 clearly show a better sensitivity of the ZSVC-based method compared to the method based on the analysis of the stator currents. 
However, to attain a better discrimination, it is suggested that other operating conditions in which the machine and specifically, the rotor segments, work under less saturated conditions are analyzed.

\subsection{Motor Working under Low-Load (Low-Saturation) Conditions}

The second study focuses on the detection of eccentricity faults when the analyzed fPMa-SynRM works under low-load conditions, and thus, less saturation. This study assumes that the operating conditions are $0.7 \mathrm{~A}_{\mathrm{RMS}}, 130 \mathrm{~V}_{\mathrm{RMS}}, 5000 \mathrm{rev} / \mathrm{min}$, and $40^{\circ}$ current angle (between $d-0^{\circ}$ and $q-90^{\circ}$ ). It is noted that a low current means a low magnetic saturation of the rotor segments.

Figure 7 shows the spectral content of the line currents of the analyzed fPMa-SynRM working under low-current and low-saturation conditions, for both healthy and $40 \%$ static eccentricity conditions.

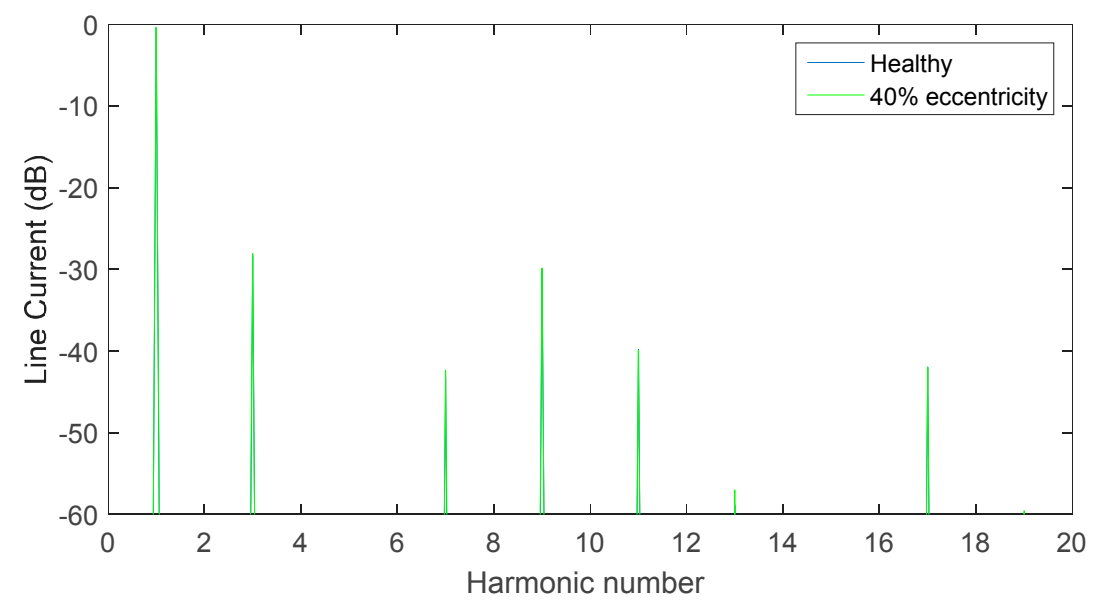

Figure 7. Low-current low-saturation operating conditions. Spectral content of the line currents. Healthy machine and faulty machine with $40 \%$ eccentricity.

Figure 8 shows the spectral content of the ZSVC of the analyzed fPMa-SynRM working under low-current and low-saturation conditions, for both healthy and $40 \%$ static eccentricity conditions.

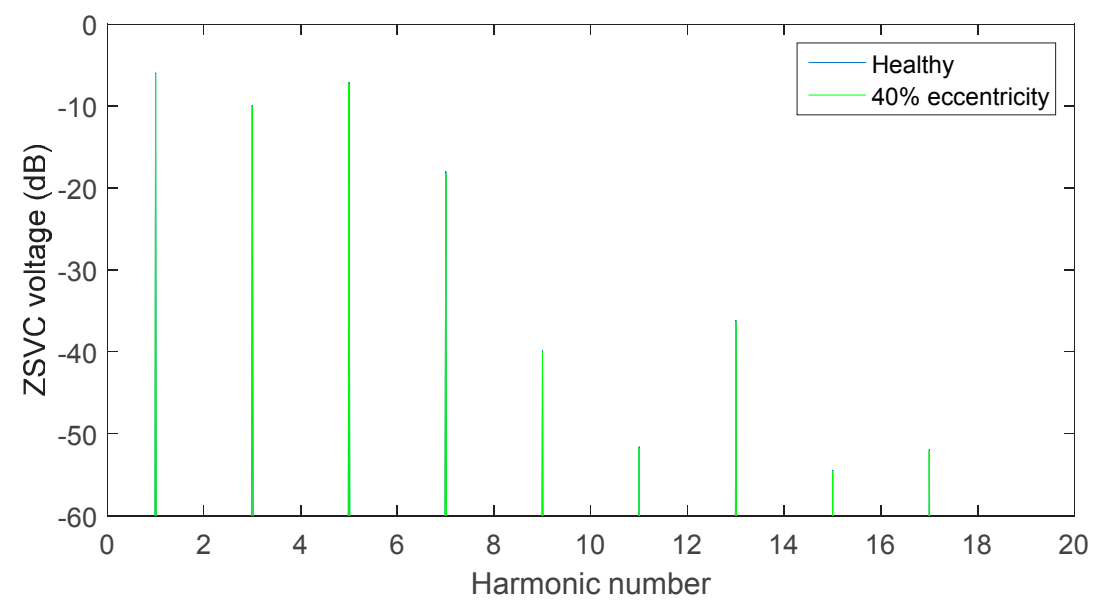

Figure 8. Low-current low-saturation operating conditions. Spectral content of the ZSVC. Healthy machine and faulty machine with $40 \%$ eccentricity.

As proved in Figures 7 and 8, the discrimination power decreases (both healthy and faulty spectra are almost superimposed) with respect to the operating point corresponding to the nominal conditions, since almost all of the magnetic flux flowing through the stator windings is due to the permanent 
magnets in the rotor, and thus, the reluctance of the path followed by the magnetic flux in the rotor is high compared to the reluctance of the air gap, thus hindering the detection of such faults.

\subsection{Motor Working under Low-Load (Low-Saturation) and near d-Position (Current Angle 30')}

In order to improve the sensitivity of the methods based on the line currents and ZSVC, the motor is analyzed when positioned close to the $d$ axis. In this position, the influence of the permanent magnets can be almost neglected, and the reluctance of the rotor path is still lower than the reluctance of the air gap, thus facilitating the detection of the analyzed faults. In addition, the low current level produces a low magnetic saturation of the rotor segments. This study assumes that the operating conditions are $0.7 \mathrm{~A}_{\mathrm{RMS}}, 150 \mathrm{~V}_{\mathrm{RMS}}, 5000 \mathrm{rev} / \mathrm{min}$, and $30^{\circ}$ current angle.

Figure 9 shows the spectral content of the line currents of the analyzed fPMa-SynRM working under low-current low-saturation conditions with a current angle of $30^{\circ}$, for both healthy and $40 \%$ static eccentricity conditions.

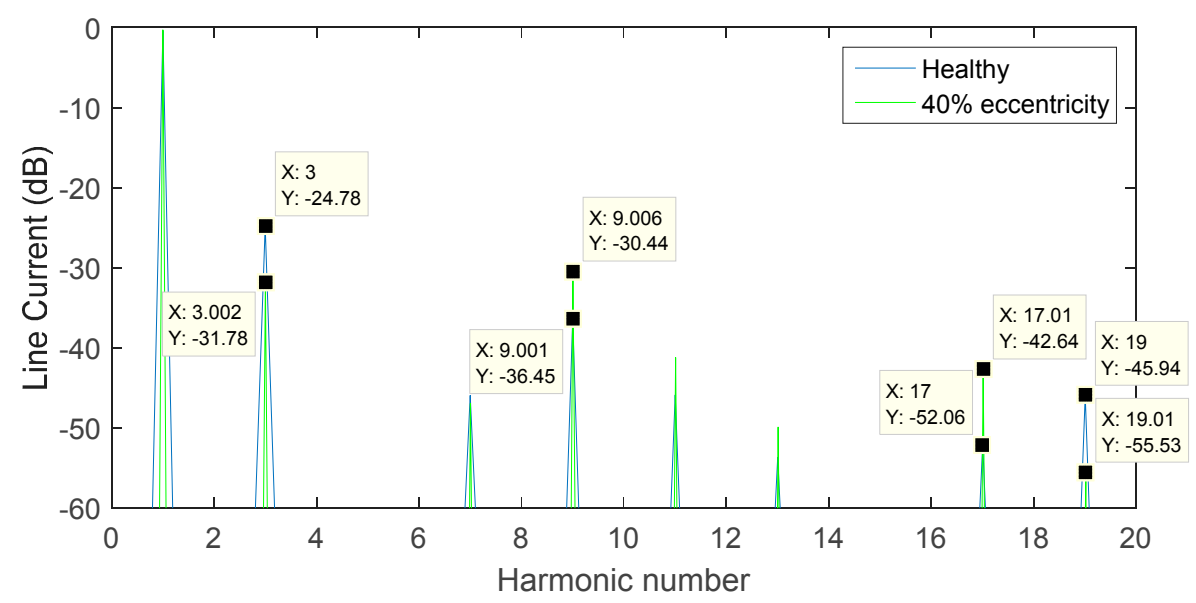

Figure 9. Low-current low-saturation operating conditions with a current angle of $30^{\circ}$. Spectral content of the line currents. Healthy machine and faulty machine with $40 \%$ eccentricity.

In this operating point, there are significant differences in the third, ninth, seventeenth, and nineteenth harmonics of the line currents, thus enabling the detection of eccentricity faults.

Figure 10 shows the spectral content of the ZSVC when the motor operates under low-current conditions with a current angle of $30^{\circ}$. It shows substantial differences in the third, fifth, and fifteenth harmonics of the ZSVC.

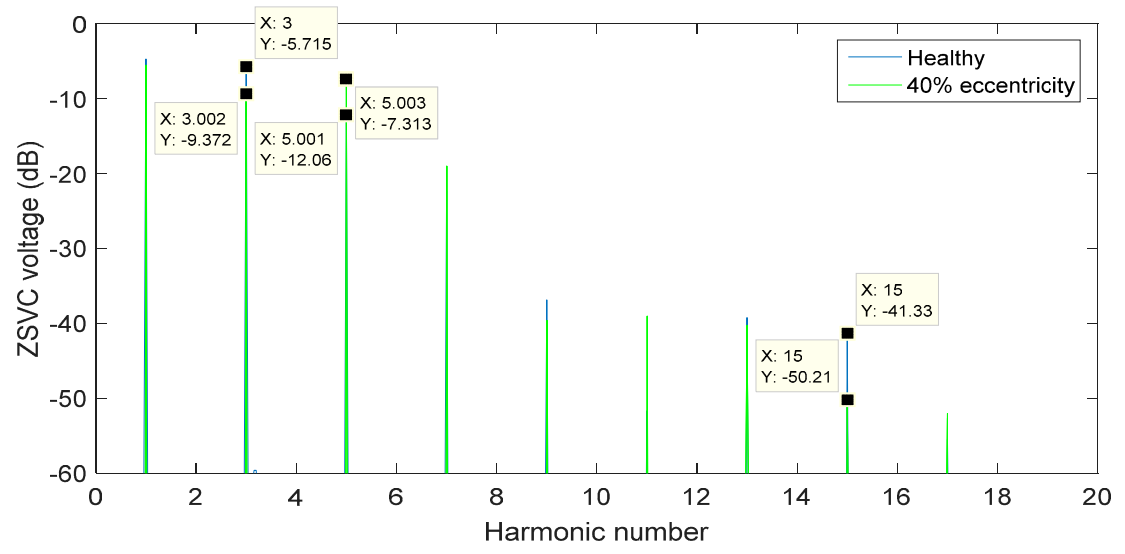

Figure 10. Low-current low-saturation operating conditions with a current angle of $30^{\circ}$. Spectral content of the ZSVC. Healthy machine and faulty machine with $40 \%$ eccentricity. 


\subsection{Results Summary}

For the sake of better readability, Tables 2 and 3 summarize the results attained in Sections 5.1-5.3.

Table 2. Spectral content of the stator currents of the analyzed fPMa-SynRM under healthy and 40\% static eccentricity conditions.

\begin{tabular}{|c|c|c|c|c|c|c|c|c|c|c|}
\hline Harmonic & 1 & 3 & 5 & 7 & 9 & 11 & 13 & 15 & 17 & 19 \\
\hline \multicolumn{11}{|c|}{ Rated operating conditions } \\
\hline Healthy (dB) & -0.34 & -16.91 & - & -24.04 & -38.25 & -42.07 & -39.00 & - & -43.31 & -54.96 \\
\hline Faulty (dB) & -0.78 & -16.82 & - & -23.76 & -34.92 & -42.87 & -37.80 & - & -48.31 & -57.15 \\
\hline$\Delta \mathrm{dB}$ & 0.44 & -0.09 & - & -0.28 & -3.33 & 0.80 & -1.20 & - & 5.00 & 2.19 \\
\hline \multicolumn{11}{|c|}{ Low-load conditions } \\
\hline Healthy (dB) & -0.39 & -28.33 & - & -43.24 & -30.06 & -39.83 & -58.81 & - & -41.99 & - \\
\hline Faulty (dB) & -0.40 & -28.08 & - & -42.34 & -29.85 & -39.88 & -57.00 & - & -41.98 & -59.54 \\
\hline$\Delta \mathrm{dB}$ & 0.01 & -0.25 & - & -0.90 & -0.21 & 0.05 & -1.81 & - & -0.01 & 59.54 \\
\hline \multicolumn{11}{|c|}{ Low-load near $d$-position conditions (Current Angle $30^{\circ}$ ) } \\
\hline Healthy (dB) & -0.40 & -24.78 & - & -45.93 & -36.45 & -45.89 & -53.65 & - & -52.06 & -45.94 \\
\hline Faulty (dB) & -0.38 & -31.78 & - & -46.94 & -30.44 & -41.21 & -49.89 & - & -42.64 & -55.53 \\
\hline$\Delta \mathrm{dB}$ & -0.08 & -7.00 & - & 1.01 & -6.01 & -4.68 & -3.76 & - & -9.42 & 9.59 \\
\hline
\end{tabular}

Table 3. Spectral content of the ZSVC of the analyzed fPMa-SynRM under healthy and 40\% static eccentricity conditions.

\begin{tabular}{|c|c|c|c|c|c|c|c|c|c|c|}
\hline Harmonic & 1 & 3 & 5 & 7 & 9 & 11 & 13 & 15 & 17 & 19 \\
\hline \multicolumn{11}{|c|}{ Rated operating conditions } \\
\hline Healthy (dB) & -1.31 & -12.61 & -20.11 & -33.85 & -34.70 & -44.29 & -36.13 & -41.51 & -55.21 & -40.73 \\
\hline Faulty (dB) & -2.36 & -13.96 & -21.17 & -40.13 & -52.41 & -35.26 & -39.82 & -46.52 & -51.38 & -51.86 \\
\hline$\Delta \mathrm{dB}$ & 1.05 & 1.35 & 1.06 & 6.28 & 17.71 & -9.03 & 3.69 & 5.52 & -3.83 & 11.13 \\
\hline \multicolumn{11}{|c|}{ Low-load conditions } \\
\hline Healthy (dB) & -5.95 & -9.89 & -7.09 & -17.98 & -39.85 & -51.57 & -36.13 & -54.42 & -51.91 & - \\
\hline Faulty (dB) & -6.12 & -10.06 & -7.26 & -18.15 & 40.02 & -51.74 & -36.29 & -54.59 & -52.08 & - \\
\hline$\Delta \mathrm{dB}$ & 0.17 & 0.17 & 0.17 & 0.17 & 0.17 & 0.17 & 0.17 & 0.16 & 0.17 & - \\
\hline \multicolumn{11}{|c|}{ Low-load near $d$-position conditions (Current Angle $30^{\circ}$ ) } \\
\hline Healthy (dB) & -4.67 & -5.71 & -12.06 & -22.25 & -36.85 & -51.68 & -39.2 & -41.33 & -55.46 & - \\
\hline Faulty $(\mathrm{dB})$ & -5.48 & -9.37 & -7.31 & -18.98 & -39.61 & -39.01 & -40.24 & -50.21 & -52.04 & _- \\
\hline$\Delta \mathrm{dB}$ & 0.81 & -3.66 & -4.75 & -3.27 & 2.76 & -12.67 & -1.04 & -8.88 & -3.42 & - \\
\hline
\end{tabular}

It is noted that bold values indicate maximum discrimination between healthy and faulty conditions, whereas the grey shading indicates the harmonics and the operating conditions selected to calculate the values of the fault indicators.

\section{The Proposed Fault Indicators}

Taking into account the results presented in Section 5, this section proposes an on-line detection using two fault indicators, $F I_{I}$ and $F I_{Z S V C}$, which are calculated as the difference between the amplitudes of the two harmonics of the stator currents or the ZSVC, respectively. It is assumed that during fault occurrence, the magnitude of the fault indicator is greater than a pre-established threshold value.

Figure 11 shows the flow chart of the proposed approach for detecting eccentricity faults. 


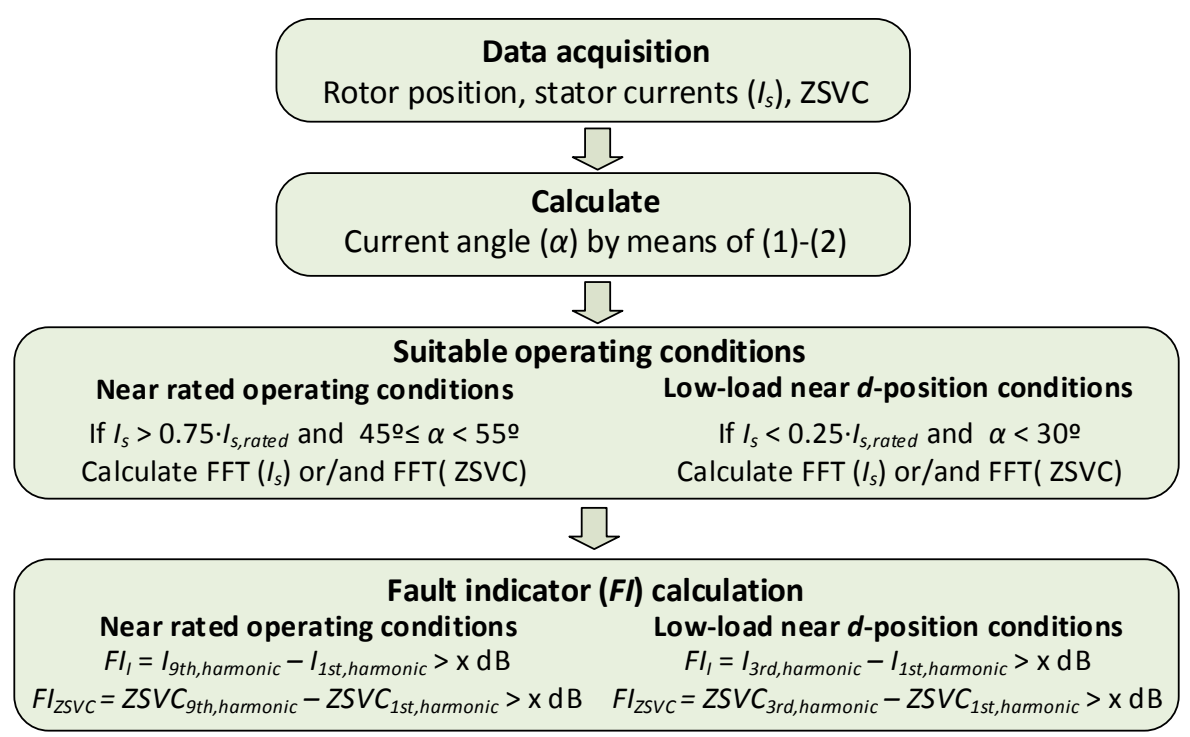

Figure 11. Flowchart of the proposed approach including the fault indicators.

The approach proposed in Figure 11 can be applied for on-line fault detection, since the rotor position, stator currents, and ZSVC can be acquired continuously, and the calculation of the current angle $\alpha$, the FFT (fast Fourier transform) of the current and ZSVC waveforms, and the fault indicators is very fast. Tables 4 and 5 summarize both the threshold value and the harmonics, which are based on the fault indicators $F I_{I}$ and $F I_{Z S V C}$ proposed in this section.

Table 4. Eccentricity fault indicator of the analyzed fPMa-SynRM based on the stator currents harmonics.

\begin{tabular}{|c|c|}
\hline Harmonic & Fault Indicator $\left(F I_{I}\right)$ \\
\hline $\begin{array}{c}\text { Near rated operating conditions } \\
\text { Healthy }(\mathrm{dB}) \\
\text { Faulty }(\mathrm{dB}) \\
\text { Threshold value }\end{array}$ & $\begin{array}{c}\boldsymbol{F I}_{\boldsymbol{I}}=\boldsymbol{I}_{\mathbf{9 t h}, \text { harmonic }}-\boldsymbol{I}_{1 \text { st }, \text { harmonic }} \\
-37.91 \\
-34.14 \\
-35\end{array}$ \\
\hline $\begin{array}{c}\text { Low-load near } d \text {-position conditions (current angle } 30^{\circ} \text { ) } \\
\text { Healthy (dB) } \\
\text { Faulty }(\mathrm{dB}) \\
\text { Threshold value }\end{array}$ & $\begin{array}{c}\boldsymbol{F I}_{\boldsymbol{I}}=\boldsymbol{I}_{3 \mathrm{rd}, \text { harmonic }}-\boldsymbol{I}_{1 \text { st }, \text { harmonic }} \\
-24.38 \\
-31.40 \\
-31\end{array}$ \\
\hline
\end{tabular}

Table 5. Eccentricity fault indicator of the analyzed fPMa-SynRM based on the ZSVC harmonics.

\begin{tabular}{|c|c|}
\hline Harmonic & Fault indicator $\left(F I_{Z S V C}\right)$ \\
\hline $\begin{array}{l}\text { Near rated operating conditions } \\
\text { Healthy }(\mathrm{dB}) \\
\text { Faulty }(\mathrm{dB}) \\
\text { Threshold value }\end{array}$ & 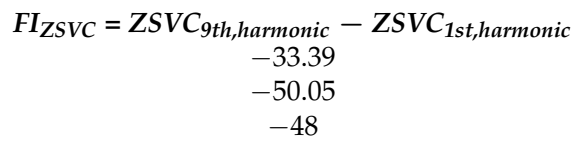 \\
\hline $\begin{array}{c}\text { Low-load near } d \text {-position conditions (current angle } 30^{\circ} \text { ) } \\
\text { Healthy }(\mathrm{dB}) \\
\text { Faulty }(\mathrm{dB}) \\
\text { Threshold value }\end{array}$ & $\begin{array}{c}\boldsymbol{F I}_{Z S V C}=\mathbf{Z S V C}_{3 r d, \text { harmonic }}-\mathbf{Z S V C}_{1 \text { st }, \text { harmonic }} \\
-1.04 \\
-3.89 \\
-3\end{array}$ \\
\hline
\end{tabular}

The values of the fault indicators shown in Tables 4 and 5 have been calculated from the amplitudes of the harmonics presented in Tables 2 and 3.

It is noted that when using a computer with an Intel core i5-6400T CPU of $2.2 \mathrm{GHz}$ and $16 \mathrm{~GB}$ of RAM, the total time required to calculate the $i_{d}$ and $i_{q}$ currents from the phase currents, the current angle $\alpha$, the FFT of the currents/ZSVC, and the faults indicators is about $3 \mathrm{~ms}$. 


\section{Conclusions}

Air gap asymmetry is a common fault in electrical machines since it has multiple origins. Eccentricity-related faults generate mechanical stress and electromagnetic asymmetries that worsen machine performance. This paper has analyzed the impact of the operating conditions employed to detect air gap asymmetry faults in fPMa-SynRMs by analyzing the spectral content of the stator currents and the ZSVC, since such faults leave a mark on their respective spectral content. The results presented in this paper clearly show that it is possible to detect eccentricity faults in five-phase fPMa-SynRMs by analyzing both the stator currents and the ZSVC spectra. The results also prove that the effects of eccentricity faults are greatly influenced by the specific operating point of the machine, and the low-current near $d$-position operating conditions are the most favorable conditions to detect such faults, since the sensitivity of both the stator currents and ZSVC spectral methods is improved. Because of the complex rotor geometry of fPMa-SynRMs, and thus, depending on the path of the magnetic flux in the rotor, the reluctance can increase dramatically, being even greater than that of the air gap, thus hindering the detection of such faults. This work has also proposed specific fault indicators for the on-line detection of eccentricity faults based on the harmonic content of the stator currents and the ZSVC, and their performance has been evaluated, thus proving the usefulness of the proposed approach.

The results summarized in this work may be valuable in designing enhanced fault diagnosis approaches in PMa-SynRMs. It is noted that although the spectral content of the stator currents may be altered by the motor controller, the ZSVC is known to be decoupled from such effects.

Future work will cover the development of methods that can be used to detect, identify, and classify different types of faults in multi-phase fPMa-SynRMs, including eccentricity, demagnetization, and short-circuit, as well as the analysis of more suitable winding configurations for detecting and minimizing the effects of such faults.

Acknowledgments: This work was supported in part by the Spanish Ministry of Economy and Competitiveness under the TRA2013-46757-R Research Project.

Author Contributions: Carlos López-Torres and Jordi-Roger Riba conceived and designed the experiments; Carlos López-Torres performed the experiments; Luís Romeral and Antoni Garcia analyzed the data; Jordi-Roger Riba wrote the paper.

Conflicts of Interest: The authors are declared no conflict of interest.

\section{Nomenclature}

$N$

$I_{0}$

$i_{a, b, c, d, e}$

$i_{d}$

$i_{q}$

$v_{a, b, c, d, e}$

$v_{0}$

$f_{\text {Eccentricity }}$

$f_{s}$

$k$

$p$

$\lambda_{a, b, c, d, e}$

$\lambda_{P M, 0}$

$R_{m}$

$\theta_{m}$

$\alpha$
Number of turns per coil [-]

Peak value of the stator current [A]

Instantaneous value of the phase current [A]

$d$-axis current [A]

$q$-axis current $[\mathrm{A}]$

Instantaneous value of the phase voltage [V]

Instantaneous value of the homopolar voltage [V]

Harmonic frequency associated to eccentricity faults $[\mathrm{Hz}]$

Electrical frequency [Hz]

Harmonic number [-]

Pole pairs [-]

Instantaneous value of the phase magnetic flux [Wb]

Instantaneous value of flux linkage due to the magnets [ $\mathrm{Wb}]$

Resistance $[\Omega]$

Rotor position [electrical ${ }^{\circ}$ ]

Current angle [electrical ${ }^{\circ}$ ] 


\section{References}

1. Riba, J.-R.; López-Torres, C.; Romeral, L.; Garcia, A. Rare-earth-free propulsion motors for electric vehicles: A technology review. Renew. Sustain. Energy Rev. 2016, 57, 367-379. [CrossRef]

2. Bonthu, S.S.R.; Choi, S.; Baek, J. Design of five-phase permanent magnet assisted synchronous reluctance motor for low output torque ripple applications. IET Electr. Power Appl. 2016, 10, 339-346. [CrossRef]

3. Bolognani, S.; Mahmoud, H.; Bianchi, N. Fast synthesis of permanent magnet assisted synchronous reluctance motors. IET Electr. Power Appl. 2016, 10, 312-318.

4. Mahmoud, H.; Bianchi, N. Eccentricity in Synchronous Reluctance Motors-Part I: Analytical and Finite-Element Models. IEEE Trans. Energy Convers. 2015, 30, 745-753. [CrossRef]

5. Zhao, W.; Chen, D.; Lipo, T.A.; Kwon, B.-I. Performance Improvement of Ferrite-Assisted Synchronous Reluctance Machines Using Asymmetrical Rotor Configurations. IEEE Trans. Magn. 2015, 51, 1-4.

6. Gupta, R.A.; Wadhwani, A.K.; Kapoor, S.R. Early Estimation of Faults in Induction Motors Using Symbolic Dynamic-Based Analysis of Stator Current Samples. IEEE Trans. Energy Convers. 2011, 26, 102-114. [CrossRef]

7. Akar, M. Detection of a static eccentricity fault in a closed loop driven induction motor by using the angular domain order tracking analysis method. Mech. Syst. Signal Process. 2013, 34, 173-182. [CrossRef]

8. Urresty, J.-C.; Atashkhooei, R.; Riba, J.-R.; Romeral, L.; Royo, S. Shaft Trajectory Analysis in a Partially Demagnetized Permanent-Magnet Synchronous Motor. IEEE Trans. Ind. Electron. 2013, 60, 3454-3461. [CrossRef]

9. Climente-Alarcon, V.; Antonino-Daviu, J.A.; Riera-Guasp, M.; Puche-Panadero, R.; Escobar, L. Application of the Wigner-Ville distribution for the detection of rotor asymmetries and eccentricity through high-order harmonics. Electr. Power Syst. Res. 2012, 91, 28-36. [CrossRef]

10. Ebrahimi, B.M.; Faiz, J.; Araabi, B.N. Pattern identification for eccentricity fault diagnosis in permanent magnet synchronous motors using stator current monitoring. IET Electr. Power Appl. 2010, 4, 418-430. [CrossRef]

11. Ebrahimi, B.M.; Faiz, J.; Roshtkhari, M.J. Static-, Dynamic-, and Mixed-Eccentricity Fault Diagnoses in Permanent-Magnet Synchronous Motors. IEEE Trans. Ind. Electron. 2009, 56, 4727-4739. [CrossRef]

12. Glowacz, A.; Glowacz, Z. Diagnosis of stator faults of the single-phase induction motor using acoustic signals. Appl. Acoust. 2017, 117, 20-27. [CrossRef]

13. Glowacz, A. Diagnostics of Rotor Damages of Three-Phase Induction Motors Using Acoustic Signals and SMOFS-20-EXPANDED. Arch. Acoust. 2016, 41, 507-515. [CrossRef]

14. Glowacz, A.; Glowacz, Z. Diagnostics of stator faults of the single-phase induction motor using thermal images, MoASoS and selected classifiers. Measurement 2016, 93, 86-93. [CrossRef]

15. Giantomassi, A.; Ferracuti, F.; Iarlori, S.; Ippoliti, G.; Longhi, S. Electric Motor Fault Detection and Diagnosis by Kernel Density Estimation and KKullback-Leibler Divergence Based on Stator Current Measurements. IEEE Trans. Ind. Electron. 2015, 62, 1770-1780. [CrossRef]

16. Choi, S.; Haque, M.S.; Arafat, A.; Toliyat, H. Detection and Estimation of Extremely Small Fault Signature by Utilizing Multiple Current Sensor Signals in Multiphase Electric Machines. IEEE Trans. Ind. Appl. $2017,1$. [CrossRef]

17. Bouzida, A.; Touhami, O.; Ibtiouen, R.; Belouchrani, A.; Fadel, M.; Rezzoug, A. Fault Diagnosis in Industrial Induction Machines Through Discrete Wavelet Transform. IEEE Trans. Ind. Electron. 2011, 58, 4385-4395. [CrossRef]

18. Ilamparithi, T.; Nandi, S. Analysis, modeling and simulation of static eccentric reluctance synchronous motor. In Proceedings of the 8th IEEE Symposium on Diagnostics for Electrical Machines, Power Electronics and Drives, Bologna, Italy, 5-8 Septembre 2011; IEEE: New York, NY, USA, 2011.; pp. 45-50.

19. Lee, S.B.; Hyun, D.; Kang, T.; Yang, C.; Shin, S.; Kim, H.; Park, S.; Kong, T.-S.; Kim, H.-D. Identification of False Rotor Fault Indications Produced by Online MCSA for Medium-Voltage Induction Machines. IEEE Trans. Ind. Appl. 2016, 52, 729-739.

20. Saavedra, H.; Urresty, J.-C.; Riba, J.-R.; Romeral, L. Detection of interturn faults in PMSMs with different winding configurations. Energy Convers. Manag. 2014, 79, 534-542. [CrossRef]

21. Urresty, J.-C.; Riba, J.-R.; Romeral, L. Influence of the stator windings configuration in the currents and zero-sequence voltage harmonics in permanent magnet synchronous motors with demagnetization faults. IEEE Trans. Magn. 2013, 49, 4885-4893. [CrossRef] 
22. Siddiqui, K.M.; Sahay, K.; Giri, V.K.; Gothwal, N. Diagnosis of airgap eccentricity fault in the inverter driven induction motor drives by transformative techniques. Perspect. Sci. 2016, 8, 127-131. [CrossRef]

23. Ebrahimi, B.M.; Javan Roshtkhari, M.; Faiz, J.; Khatami, S.V. Advanced Eccentricity Fault Recognition in Permanent Magnet Synchronous Motors Using Stator Current Signature Analysis. IEEE Trans. Ind. Electron. 2014, 61, 2041-2052. [CrossRef]

24. Mahmoud, H.; Bianchi, N. Eccentricity in Synchronous Reluctance Motors-Part II: Different Rotor Geometry and Stator Windings. IEEE Trans. Energy Convers. 2015, 30, 754-760. [CrossRef]

25. Pazouki, E.; Islam, M.Z.; Bonthu, S.S.R.; Choi, S. Eccentricity fault detection in multiphase permanent magnet assisted synchronous reluctance motor. In Proceedings of the 2015 IEEE International Electric Machines \& Drives Conference (IEMDC), Coeur d'Alene, ID, USA, 10-13 May 2015; IEEE: New York, NY, USA, 2015.; pp. 240-246.

26. Yang, X.; Kou, B.; Luo, J.; Zhou, Y.; Xing, F. Torque Characteristic Analysis of a Transverse Flux Motor Using a Combined-Type Stator Core. Appl. Sci. 2016, 6, 342. [CrossRef]

27. Saavedra, H.; Riba, J.-R.; Romeral, L. Multi-objective Optimal Design of a Five-Phase Fault-Tolerant Axial Flux PM Motor. Adv. Electr. Comput. Eng. 2015, 15, 69-76. [CrossRef]

28. Ilamparithi, T.C.; Nandi, S. Detection of Eccentricity Faults in Three-Phase Reluctance Synchronous Motor. IEEE Trans. Ind. Appl. 2012, 48, 1307-1317. [CrossRef]

29. Romeral, L.; Urresty, J.C.; Riba Ruiz, J.R.; Garcia Espinosa, A. Modeling of surface-mounted permanent magnet synchronous motors with stator winding interturn faults. IEEE Trans. Ind. Electron. 2011, 58, 1576-1585. [CrossRef]

30. Ebrahimi, B.M.; Faiz, J. Configuration Impacts on Eccentricity Fault Detection in Permanent Magnet Synchronous Motors. IEEE Trans. Magn. 2012, 48, 903-906. [CrossRef]

31. Faiz, J.; Ebrahimi, B.M. Static Eccentricity Fault Diagnosis in an accelerating no-load three-phase saturated squirrel-cage induction motor. Prog. Electromagn. Res. B 2008, 10, 35-54. [CrossRef]

32. Welchko, B.A.; Lipo, T.A.; Jahns, T.M.; Schulz, S.E. Fault Tolerant Three-Phase AC Motor Drive Topologies: A Comparison of Features, Cost, and Limitations. IEEE Trans. Power Electron. 2004, 19, 1108-1116. [CrossRef]

33. Wallmark, O.; Harnefors, L.; Carlson, O. Control Algorithms for a Fault-Tolerant PMSM Drive. IEEE Trans. Ind. Electron. 2007, 54, 1973-1980. [CrossRef]

34. Urresty, J.-C.; Riba, J.-R.; Romeral, L. A back-emf based method to detect magnet failures in PMSMs. IEEE Trans. Magn. 2013, 49, 591-598. [CrossRef] 